\title{
Confronting storms, fires, and pestilence: Meaningful evaluation for a hazardous world
}

\author{
Juha I. Uitto
}

\section{Introduction}

The world as we know it would appear to have suddenly become more hazardous than ever before in our living memory. This may not actually be so considering the entire hazardscape, but the types of societal threats have changed. The sweet complacency of the affluent West has been disrupted. Instead of history ending in an unstoppable march of globalisation and economic growth, we are suddenly faced with natural and social calamities that threaten the sustainability of our common future. Even the original author of the end of history thesis has seen the extraordinary chaos in which the world finds itself now and has revised his vision (Fukuyama, 2006, 2020). Of course, smooth sailing was always an illusion. The triumph of free markets and capitalism that would benefit everyone in all corners of a peaceful world was always post-Cold War hubris. The rising tide never even started to lift all the boats at the same rate. The global environmental degradation and depletion of natural resources has continued at an 
accelerated pace, although new technologies have bought us time and allowed us to gain certain efficiencies and to exploit new frontiers. These same technological advances have also brought new threats.

Now it is all catching up with us: climate change, species extinction, a deadly pandemic, civil unrest, and the rise of oppressive populism are all causes of global concern for the future of humanity. Against this backdrop, it is imperative to rethink the role of evaluation so that it can truly become a constructive force in contributing to solutions to pressing global challenges. In its current form, evaluation is often relegated to a role of tinkering at the margins, a role many evaluators seem to have willingly accepted. We are mostly concerned with technical questions about addressing symptoms of the global problems through projects, checking whether these projects achieved their internal goals irrespective of what goes on around them. We tend to be engaged in accounting exercises instead of critical learning that constructively contributes to our common future. There is, however, an emerging movement among the evaluation community that wants to move the field towards a proactive contributor to a more sustainable world.

Before looking at the role of evaluation in development and transformational change, the root causes of destruction are examined, along with the maldistribution of the repercussions of this destruction. It is argued that evaluation must take a broad view within a complex system that includes the natural environment if it is to make a contribution to a world that is socially, economically, and environmentally sustainable.

\section{A bad beginning for a new decade}

The years 2020 and 2021 have been defined by the COVID-19 pandemic which, by April 2021, had infected almost 138 million people 
and killed almost 3 million around the world. ${ }^{1}$ At that time the highest death toll $(565,000)$ was in the world's most powerful country, the United States (the United States has about $4 \%$ of the world population, but $19 \%$ of the deaths). It was closely followed by Brazil (359,000 deaths), Mexico (210,000), and India (172,000), three middle-income countries that were supposed to prove how unfettered markets would lift developing countries to the centre of the global economy.

The pandemic has impacted on various social and ethnic groups in very different ways. In the United States, Black, Indigenous, and other coloured people (BIPOC) have suffered disproportionately due to the high impacts of COVID-19 from many different factors, most related to systemic long-term discrimination and inequality. ${ }^{2}$ At the same time, the pandemic has pitched different groups of people against one another. In several countries, and especially in the United States, we have seen protests against business closures and mask wearing by people who see these as infringements on their freedoms and individual rights - or who believe the entire pandemic to be intentional misinformation created by government groups in order to control individual liberties. In the United States, these protests have taken place during a time when there have been exceptionally large and broad-based demonstrations against police brutality in reaction to repeated killings of Black people. When these protests have occasionally turned riotous, the participants have been described as criminals and thugs, while intimidating caravans of heavily armed militia types demand an end to mask-wearing mandates and are described by some as defenders of freedom. Inevitably, there have been clashes between the various sides which on occasion have turned deadly.

1 Figures from the Johns Hopkins University dashboard downloaded on 14 April 2021: https:// www.arcgis.com/apps/opsdashboard/index.html\#/bda7594740fd40299423467b48e9ecf6

2 http://info.primarycare.hms.harvard.edu/blog/covid-social-determinants-health 
Climate change is contributing to unprecedented wildfires. Disastrous fires devastated much of Australia in 2019 and ravaged the American West Coast, from California up to Oregon and Washington State and later Colorado in 2020. They have burned through millions of hectares with tragic consequences to wildlife and lost habitat, and material losses to property owners. The economic losses have been estimated to be at least US\$20 billion. ${ }^{3}$ The smoke from the fires has worsened air quality in distant places and rendered sunsets unusually red in places as far afield as Finland. In 2021, parts of northern India and Nepal are experiencing forest fires that are the worst in 15 years. ${ }^{4}$ These fires in themselves are major contributors to greenhouse gases. The world's largest tropical forest, the Amazon, is also burning, with a $60 \%$ increase in fire locations as compared with 2019. Many of these fires have been intentionally set to clear forest for agriculture, an illegal process that has been encouraged by misguided policies and corruption. The Amazon climate is also getting drier due to climate change, which makes the situation worse. A recent study led by the Stockholm Resilience Centre predicts that up to $40 \%$ of the Amazon rainforest could turn into a savanna within this century (Staal et al., 2020). Pantanal, the world's largest wetland adjacent to the Amazon, has been ravaged by "apocalyptic" fires and there are fears that the unique ecosystem with its rich flora and fauna will never recover (Rodriguez Mega, 2020).

The year 2020 also saw a record-breaking Atlantic hurricane season. When a tropical depression formed in the Caribbean on 24 October and strengthened into a hurricane called Zeta 2 days later, it became the 26th major storm of the season to affect the region, against a normal yearly average of 12 . The frequency and strength of these storms led the US National Oceanic and Atmospheric

3 https://www.bbc.com/news/world-us-canada-54180049

4 https://www.bbc.com/news/world-asia-india-56671148 
Administration (NOAA) to adopt stronger language to communicate clearly about specific hazards so that people better understood the potential impacts and significance of these storm events and could make decisions as to when to evacuate (Moran, 2020). Cases where COVID-19 complicated hurricane evacuations were reported, thus demonstrating the notion of overlapping and complex disasters. ${ }^{5}$ Elsewhere, we have seen similarly extraordinary storm activity. While the number of tropical cyclones in the Pacific was lower than average, Northeast Asia (Japan, Republic of Korea, and DPR Korea) was pummelled particularly hard.

If there is one conclusion from both the pandemic and the climate-related disasters, it is that societies remain extremely vulnerable to natural hazards. Irrespective of how sophisticated our societies become, we do not control the forces of nature that can wreak tremendous havoc upon us, and our technological and governance systems are not able to cope. It is clear that humans remain a part of the broader ecosystem and completely dependent on it. We need transformational change that will modify how we interact with the natural environment and with one another. In the midst of the urgent action needed to deal with these issues, there are some signs of hope. The 2030 Agenda for Sustainable Development ${ }^{6}$ and its attendant 17 Sustainable Development Goals (SDGs) were adopted by 198 United Nations member states in 2015. In the same year, countries agreed on the Sendai Framework for Disaster Reduction, ${ }^{7}$ which recognises climate change and variability as important factors for disaster management. In the following year, the ambitious Paris Agreement ${ }^{8}$ on climate change came into effect with the aim of limiting global temperature rise this century to below 2 degrees Celsius above pre-in-

5 https://www.cdc.gov/disasters/hurricanes/covid-19/prepare-for-hurricane.html

6 https://sustainabledevelopment.un.org/post2015/transformingourworld

7 https://www.undrr.org/publication/sendai-framework-disaster-risk-reduction-2015-2030

8 https://unfccc.int/process-and-meetings/the-paris-agreement/the-paris-agreement 
dustrial levels. Established public funding mechanisms for the global environment have proliferated, including the Global Environment Facility (GEF), ${ }^{9}$ the Green Climate Fund (GCF), ${ }^{10}$ and the Climate Investment Funds. ${ }^{11}$ The Climate Policy Initiative estimates that the total annual flows of climate finance from both public and private sources rose to US\$632 billion in 2019-2020 (CPI, 2021).

Despite these unprecedentedly high international commitments, it is clear that the combined funding and resulting actions will not actually maintain global warming within the desired limits. Many governments are still subsidising non-renewable energy, industrial-scale agriculture, and other environmentally harmful practices. These financial flows are orders of magnitude larger than those invested in clean, low-carbon initiatives. According to IMF, the global subsidies to fossil fuels were US\$5.9 trillion in 2020 (Parry et al., 2021). Consequently, while climate-change mitigation remains a high priority, it will be necessary to invest heavily into adaptation strategies and action (GCA, 2019).

\section{Root causes of destruction}

The root causes of these complex problems all relate to rampant consumerism, monetarism, and the neglect and abuse of the natural environment. For centuries, humanity has been using the natural environment as an inexhaustible source of raw materials and a sink of waste. When one resource becomes exhausted, we move on. In the past, this moving on meant literally new continents to be exploited, notably North and South America, and later Africa, Asia, and Australasia (Worster, 2016). This expansion of the frontier continues today, as humanity continues its penetration deeper into hitherto

9 http://www.thegef.org/

10 https://www.greenclimate.fund/

11 https://www.climateinvestmentfunds.org/, 
unexploited ecosystems in the remaining wilderness areas. As the planet warms, this makes both the Arctic and Antarctic resources more accessible for exploitation and destruction. This is driven by an intense search for new raw materials and minerals and by making space for agriculture and human habitation and transportation. With the current lifestyles, it has been calculated that the world could sustainably support a human population of a maximum of 3 billion people (Tucker, 2019). Instead, the world population is expected to grow from the current 7.7 billion to 9.7 billion in 2050 (UN, 2019).

Most deforestation is driven by three commonly used agricultural products - soybeans, palm oil, and beef cattle-which together cause almost $80 \%$ of all the tropical deforestation in the world (Brack et al., 2016). Cattle ranching is highly destructive: there are currently some half a billion cows in the world and 23 billion chickens. All of these animals that we grow for our own food need to eat, too; consequently, more land is now cleared for growing animal feed than is planted in food crops for people. For example, a large part of the soybean production in the world is required to support extensive pig farms. The fires that are currently burning in the Amazon are mostly initiated by clearing land for agriculture.

Deforestation and the continual destruction of habitats is the root cause for the widespread loss of biological diversity. These environmental impacts of human origin are all interlinked with the current pandemic. The virus that causes COVID-19, SARS-CoV-2, is zoonotic, like most of the other viruses that have caused the epidemic diseases of recent decades: SARS, MERS, H1N1, and others. Zoonotic viruses spill over from non-human hosts to humans who come into contact with them. Such contacts may happen through markets where domesticated or wild animals are sold-dead or alive-for meat, traditional Chinese medicine (TCM), and for other purposes. Habitat destruction is also bringing wild animals closer 
together with densely populated human settlements and favours animals that thrive in human contact, such as rats and bats. Research confirms that disease outbreaks increase in areas with deforestation or where biological diversity is lost (Tollefson, 2020). Zoonoses constitute about $60 \%$ of all infectious diseases and three-quarters of the emerging diseases now facing humanity (Asokan \& Asokan, 2016).

While the precise type of virus and the timing of its emergence were impossible to predict, the fact that a zoonotic coronavirus would cause a pandemic was known. There had been four pandemics since 1918. Scientists had highlighted the risk and warned for preparedness for years and governments had set up taskforces, designed infectious disease plans, and organised simulations on how to deal with such outbreaks. Still, no country was fully prepared for the rapid spread of the infection across the globe, which was facilitated by the characteristics of the virus itself - the fact that it is contagious through airborne transmission, even if the carrier shows no symptoms-as well as the highly mobile human population in a connected world. In 2019, there were 3 billion airline passengers flying across the world largely unchecked.

There are significant parallels between the pandemic and climate change. First of all, the driving forces are largely the same: a rise in human population pressures and an ever-expanding economy based on unrestricted exploitation of natural resources and globalisation. The largest sources of greenhouse-gas emissions are from fossil fuels for energy production (including industrial uses, construction, heating, and cooling), transport (spurred by the rapid rise of vehicles in cities and towns, air travel, and ship-based transportation of goods), and agriculture. ${ }^{12}$ Land-use change is a major factor, especially with the extensive and ongoing destruction and removal of forests and habitats, as healthy forests act as a major greenhouse-gas sink.

12 https://www.epa.gov/ghgemissions/sources-greenhouse-gas-emissions 


\section{Unequal repercussions}

Another parallel between the pandemic and climate change pertains to social factors and consequences. In both cases, people's vulnerability is not randomly distributed; it is a function of variable exposure to risk and people's ability to cope with it. Vulnerability to climatic hazards is equally a function of social, economic, and political factors (Surjan et al., 2016). Those in a weaker position economically, socially, ethnically, and politically are generally more vulnerable to the negative side effects of pandemics and climate change, such as economic disparity and environmental degradation. The exposure and capacity to cope with these types of adverse events and their various effects varies significantly between different groups of people and communities. This again can be demonstrated for different communities. Indigenous peoples in the Amazon, for example, have been devastated by the virus through exposure to outsiders-including loggers, miners, and agriculturalists. Indigenous communities have suffered distressing effects due to their normal isolation and lack of resistance to new infectious diseases. They also lack the financial resources and access to healthcare services that can help them cope.

Women tend to be more directly reliant on natural resources for their livelihoods, as they are often engaged as small farmers and fisherfolk in the developing countries, which renders them vulnerable to variations in climate and hydrological conditions. The gender dimension to vulnerability is recognised in the United Nations Framework Convention on Climate Change ${ }^{13}$ and by others. For example, small farmers, the majority of whom are often women, eke out their existence on marginal lands in Africa, where they rely on their own local agricultural produce for nutrition and income to make a meagre living. In these rural areas, small variations in rainfall patterns

13 https://unfccc.int/gender 
can mean the difference between eating and hunger, between coping and poverty. An evaluation conducted by the GEF Independent Evaluation Office (IEO) of the facility-supported programmes in the Sahel demonstrated how vulnerability in the region is increasing with prolonged droughts and increasing human pressure on land and water resources, thus highlighting the need to integrate environmental considerations with development that enhances local livelihoods (GEF IEO, 2020a).

Low-lying coastal regions and countries are particularly vulnerable to storms and rising sea levels. This is equally true for the Netherlands as it is for Bangladesh; however, a rich country with adequate resources, a well-educated population, and a strong governance system is in a much better position to plan for and cope with hazards. In coastal Bangladesh, sea-level rise and associated salt-water intrusions threaten agricultural crop and aquaculture production with multiplier effects on poor people's ability to grow food and to pay for necessities, such as housing and school fees (Baer \& Singer, 2018, pp. 105-107). For many of the low-lying islands in the world, particularly small island developing states (SIDS), this is more a matter of continued existence (UN, 2015). In many urban centres, particularly in developing countries, migrants from the countryside live in informal settlements, often on unstable slopes susceptible to storms, floods, and landslides and depend on minimal resources to sustain their families. As hazardous events increase in frequency and magnitude with climate change, their vulnerability increases. These local examples of vulnerability and hardship often add up to large measurable and cumulative changes at the macro level.

For coastal cities where a third of the world's population now live-from Tokyo to New York to Lagos_the losses will be large and extremely costly and will require massive relocations of people and infrastructure. This is likely to cause major upheaval and require 
greater resourcing and materials than are currently available. Again, geographic areas and countries with stronger economies and efficient governance systems have a major advantage to deal with risks and hazards than ones with lower socioeconomic status. Generally, in all situations, risk and uncertainty will hamper effective planning (Fuchs et al., 2011). It is no coincidence that the Global Adaptation Index ${ }^{14}$ (ND-GAIN) developed by the Notre Dame Adaptation Initiative ranks Norway, New Zealand, Finland, Denmark, and Sweden as the top five countries with the capacity to adapt well. The bottom countries on the list are all poorer developing countries (including the Democratic Republic of Congo, Eritrea, Somalia, Central African Republic, and Chad), all exhibiting serious problems, including growing poverty and poor governance.

On a global scale, there is an increased blurring between "developing" and "developed" (or industrialised) countries in terms of economics and standards of living, and also the widening inequalities between the rich and the poor within the countries. This is exemplified by the emergence of large middle-income countries, notably China, India, and Brazil, with still large populations in poverty. Social and economic disparities are marked and exaggerated in the United States and growing in parts of Europe. Globalisation has mainly benefited the well-educated, largely urban people, over those less educated and poorer. Growing inequities are leading to increased division, distrust, and unrest in many wealthy countries.

Throughout the world, vulnerability, fragility, and conflict have increased, which is being exacerbated by climate change. Research has shown that risk of conflict can be directly attributed to deviations from average temperatures experienced through warming and changing rainfall patterns (Burke et al., 2015). Conflict and a lack of

14 https://gain.nd.edu/ 
employment opportunities, partially caused by environmental degradation alongside poor governance, are increasingly causing people to move in search of better livelihood opportunities and security. Nationalistic tendencies and xenophobia in many countries have also caused a backlash towards immigrants. This is further fuelled by a fear of migrants bringing in disease and crime, which has led to tighter restrictions, increasing barriers to migration, and closing the borders in many rich countries. The United States has nearly closed its borders to Central American migrants who are migrating north largely because of poor job opportunities, violence, crime, and corruption in their home countries. Climate change and environmental degradation are exacerbating the problem and making it harder for them to eke out a living of their land (Aguirre, 2020). In terms of climate change, small island developing states are in a precarious situation as the effects are becoming increasingly acute; and people will be forced to migrate. The links between environmental degradation, climate change, and migration are extremely complex, and people do not simply decide to move just based on environmental factors (McMichael et al., 2020).

On a positive side, many vulnerable groups also have strong capacities that can help them cope with crises, not least through their thorough understanding of issues facing them and their locales. Women's participation and leadership in both political processes and concrete actions to tackle climate challenges will lead to demonstrably better outcomes (GEF, 2018). Similarly, indigenous peoples' anchoring in place and local knowledge can be an important asset in enhancing their resilience (Ford et al., 2020). To enable us to better manage the complex and closely interlinked problems, we need to know the extent of these issues and the causal factors leading to change, alongside local protective factors. We therefore need to have a meaningful system for assessing and gauging these factors and their interactions. 


\section{Measuring development}

Evaluation is part of a suite of approaches developed to identify incremental change and assess progress, using criteria governed by a set of standards. In addition, evaluation provides a way to enable reflection, and assist the identification of future change. All the developments and the potential repercussions described above need to be carefully examined and assessed in order to determine how we best define and measure societal advancement.

Over the past century or so, the most commonly used measure of development by governments and international organisations, such as the World Bank, is the Gross Domestic Product (GDP), which sums up all the goods and services a national economy produces. What GDP does not capture is natural capital and the depreciation of that capital, nor does it measure human, social, institutional, or political capital. In terms of natural capital, a country may be destroying its natural resources on which the economy depends, and still show positive trends in GDP growth. A fundamental flaw in national accounting for most countries is that there is an almost exclusive focus on measuring economic and financial capital. However, other capitals such as social and human capital in terms of health, education, gender equality, and so forth are gaining traction as important criteria to collect and measure. Still, most social indicators are usually considered in terms of productivity of labour force and population rather than wellbeing per se.

Natural capital on which virtually all human endeavour depends is seldom considered in these national assessments. According to the World Bank, $47 \%$ of the wealth of the developing countries depends directly on natural resources. ${ }^{15}$ This is a clear underestimate for both developing and industrialised countries as it only takes into

15 https://www.worldbank.org/en/topic/natural-capital 
account the direct contributions of natural resources to the economy. It ignores most of the ecosystem services, such as climate, clean air and water, soil, vegetation, cultural services, recreation and so forth, which all provide provisioning, regulating, and supporting services to maintain and enhance natural capital, mitigate risk, and help protect against a range of hazards including cyclones, storms, sea-level rise, droughts, fires, etc. Narrow economic measures such as GDP completely ignore the intrinsic values that support life and wellbeing, including those values derived from natural ecosystems, habitats, and biodiversity. As the pandemic of 2020-21 has shown us, human health is directly dependent on ecosystem health.

Increasingly, some countries are exploring broader measures that include social and environmental considerations. One of the first was Bhutan, which developed its own unique measure of Gross National Happiness. ${ }^{16}$ Aotearoa New Zealand uses the Living Standards Framework $(\mathrm{LSF})^{17}$ in government budget-making. The LSF encourages thinking about policy impacts across different wellbeing dimensions and long-term distributional issues across people, places, and generations. The LSF requires projects to be evaluated based on their wellbeing contributions in terms of human, social, natural, and financial and physical capitals. Such frameworks are a major step forward and are likely to be emulated more widely.

Importantly, China, having achieved its remarkable transition from a predominantly poor peasant economy three decades ago to the world's largest economy today through a singular focus on economic growth, appears to be realising the need to change its focus. China's new 5-year plan has significantly lowered the expected growth rates (which some observers consider a disappointment; Han

16 https://www.grossnationalhappiness.com/

17 https:/www.treasury.govt.nz/information-and-services/nz-economy/higher-living-standards/ our-living-standards-framework 
\& Freymann, 2021). Meanwhile, local governments are experimenting with new measures of success. The most advanced is Shenzhen, the thriving hub in the southern Guangdong Province, which in March 2021 launched a new "Gross Ecosystem Product" accounting system that incorporates three categories: (i) ecosystem goods and services that can be marketed (such as agriculture and fisheries); (ii) nonmarketable services (such as carbon sequestration by forests); and (iii) cultural and touristic benefits (Ye, 2021).

At the global level, the United Nations Development Programme (UNDP) for the first time in the 30-year history of its series of human development reports introduced planetary pressures in terms of $\mathrm{CO} 2$ emissions and material footprint into its measurement (UNDP, 2020). This innovation revealed how many of the most successful countries have supported their high human development by overexploitation of the natural environment. As these initiatives spread, they have the potential of doing more good for sustainability and the environment than any projects.

\section{State of evaluation}

Evaluation is rooted in the same Western economic tradition that places an emphasis on economic growth. As a profession, evaluation has its roots in comparative studies, with a central objective to explain which interventions produce desirable outcomes in terms of effectiveness and efficiency. One of the founders of evaluation, Donald T. Campbell, ${ }^{18}$ saw social experimentation as a route to a society where politics would play a lesser role in policymaking: policies would be tested against each other for their workability. Much of evaluation as it is practised today is based on approaches honed in education, health, and social services. Experimental and quasi-experimental approaches, often seen as desirable in evaluation, have been

18 https://campbellcollaboration.org/about-campbell/history.html 
borrowed from medicine. These, however, have limitations in terms of explanatory power, external validity, and their ability to take the broader context into account (e.g., Bickman \& Reich, 2009).

Of course, evaluation as a field is much broader and there is a variety of approaches in use, with varying emphases on quantitative and qualitative methodologies. Overall, theory-based approaches to evaluation (Stame, 2004; Weiss, 1997) are prevalent in many organisations that want to evaluate the effectiveness of their programmes and also understand the factors and mechanisms that contribute to these. Environmental evaluation emerged relatively late and is defined by complexity, which is manifested both in the nature of environmental problems and the policies and programmes designed to address them (Birnbaum \& Mickwitz, 2009).

A fundamental problem pertains to seeing an individual project as both the primary agent of change in a particular situation and, consequently, the object of evaluation. Additionally, there is an effort to minimise the costs of that project to the donor agency, rather than ascertaining the best outcomes for the intended beneficiaries. While projects remain useful tools for delivering goods and services, seldom do they alone succeed in bringing along what can be called transformational change (nor are they often intended to do so). When evaluations take a project as the unit of account they tend to focus on the project's internal logic. Most projects today have some form of theory of change, which identifies impact pathways through which the intervention intends to achieve its objectives. Project designers at times insert major assumptions that add up to little more than wishful thinking, which will ultimately render a project as an exercise in futility: such as, "all government departments will support the policy directions" or "the market environment will remain stable". The risks will be the opposite of these. It is easy to see why these types of assumptions and risks have a potentially dramatic effect on 
each individual project, which has no control over the broader policy environment or market conditions in which it operates.

Risks related to climate change are complex and highly variable. They vary dramatically from area to area and are related to probabilities of events, such as frequency and magnitude of major storm events, flooding, wildfires, shifting rainfall patterns, drought, and sea-level rise. This added complexity and required assumptions must be added to all project designs, but very seldom are. Even in cases in which "killer" assumptions and risks do not materialise and the project achieves the objectives set for it, it seldom makes the impact on the larger problem that provided its original justification. Too many projects address the symptoms rather than the root causes of problems. When an evaluation uses a project as the unit of account and looks only at its internal logic, it often misses the big picture; that is, the broader context where the project takes place and interacts with everything else, ranging from other projects to market conditions, to national policies and harmful subsidies that are often so large and complex that they prevent the project from making a dent. Furthermore, current project-level evaluations based on internal logic models don't often account for unintended consequences, whether positive or negative. However, it is safe to assume that all interventions have some unintended effects-often environmental or social - that were not foreseen by the proponents.

In a world where there are competing needs for limited resources, it is natural to attempt to identify interventions that provide the best value for money, that deliver the largest amount of benefits for the least amount of resources. Effectiveness and efficiency are something to strive for. In the GEF, we have conducted value-for-money evaluations and tried to identify win-win situations regarding strategies that target multiple environmental goals (for instance, sustainable forest management, land degradation, biodiversity and carbon 
sequestration) or environmental and socioeconomic benefits (e.g., GEF IEO, 2017, 2018a). Even if focusing on a single intervention, it is important for the evaluation to place the evaluand into the larger context and assess whether it makes a desired positive difference.

\section{Towards transformational change}

As formulated by Patton (2020), "evaluating transformation is different from evaluating projects and programs" (p. 22). This does not mean that narrowly defined interventions, such as projects, are always doomed to fail; however, they do need to be designedand evaluated - with a broader context in mind. In GEF funding there has been a marked shift towards programming that targets the drivers of global environmental degradation. This has meant a stronger focus on political, social, and economic conditions using a variety of tools, which enable and incentivise sustainable use of natural resources and ecosystem management and address climate change. An evaluation conducted by the Independent Evaluation Office in six countries (Belarus, Brazil, Kazakhstan, Namibia, the Philippines, and Vietnam) confirmed that addressing tools such as policy, regulatory, and legal frameworks is often an effective way of promoting environmentally sustainable development (GEF IEO, 2018b).

Another evaluation (GEF IEO, 2018c) homed in on common factors that would lead to deep and systemic long-term changes towards environmentally sound development. We took a purposive sample of completed projects identified by GEF agencies ${ }^{19}$ as having achieved transformational change, verified by project-level terminal evaluations, and analysed them systematically for factors that

19 The United Nations Development Programme (UNDP), UN Environment Programme (UNEP), The World Bank, Food and Agriculture Organization of the UN (FAO), and the Asian Development Bank (ADB). 
contributed to their success. Transformational change was defined as a deep, systemic, and sustainable change with large-scale impact in an area of global environmental concern. Factors leading to transformational change included:

- Having a clear ambition in the design-All successful projects were found to have ambitious goals aimed at addressing the systemic bottleneck or market distortion that acted as the root cause for global environmental concern.

- Addressing market or system reform through policies-The depth and scale of reforms promoted in all projects was deeply influenced by a prevailing policy environment, which first had to be addressed.

- Determining mechanisms for financial sustainability-All the transformational interventions established mechanisms for financial sustainability either by leveraging market forces and key stakeholders' economic interests or by integrating the changes within government budgetary systems.

- The quality of the implementation and execution-Perhaps self-evidently, all successful interventions were managed, implemented, and executed well.

The evaluation found that transformational change was not necessarily dependent on massive investments but could be achieved by projects of different size. For instance, the Uruguay Wind Energy Program, financed by the GEF and implemented by UNDP, fulfilled these criteria. It was launched in 2007 to help eliminate barriers to the development of commercially viable wind-energy investment. It came at a time when there was strong political support in the country to diversify energy sources (the country had virtually exhausted its hydropower potential). The project managed to create a competitive and transparent wind-energy market with a stable 
framework for investment and adequate tariff incentives to attract private sector investment. At the beginning of the project, Uruguay did not have any established wind power; by 2016, wind generated $33 \%$ of the country's energy. This was achieved with a GEF grant of US\$950,000 with US\$53.8 million in funding from the government to the national wind-energy programme.

\section{Where evaluation should be}

The above examples show the importance of focusing on the big picture, even if the resources dedicated to a particular intervention are limited. It is important to open up to a systems perspective, which sees every intervention - whether a project, programme, strategy, or policy-operating in a broader complex landscape. There is a growing focus on systems perspectives in evaluation that recognises the importance of complexity in addressing and evaluating challenges, such as global environmental change, pandemics, and growing inequalities (McGill et al., 2021; Picciotto, 2020; Williams, 2015). In practice, this will call for an open theory of change that takes this broader landscape into account and interrogates how the intervention interacts with the various parts of the system. The GEF experience also confirms that focusing on the policies and markets can produce more transformational change than just a narrow focus on technical solutions. Evaluators, like project proponents, should learn to see every intervention through the lens of sustainability. The 2030 Agenda and the SDGs are premised on the principle that the social, economic, and environmental dimensions are all needed. If an intervention does not address each of these dimensions, it is unlikely to be durable or lead to a more sustainable situation. Evaluations must assess interventions against a hard criterion: if it doesn't contribute to a transformation towards sustainability, does the intervention have worth? 
The transformative paradigm to evaluation is intended to promote social justice, especially with marginalised communities (Mertens, 2008). Social justice, together with environmental soundness, are at the heart of the sustainable development agenda. Gender equality and women's empowerment is one of the mainstays of environmental sustainability and should thus be a standard feature in evaluations (GEF IEO, 2018d). Perspectives of indigenous peoples are particularly pertinent to evaluation of environmental and sustainable development programmes and policies. Indigenous peoples are custodians of most of the remaining pristine lands and they often take a holistic view of the world, respecting nature and placing humans firmly into the natural realm-bringing "forward the wholeness of knowledge, not just its parts" (Aluli-Meyer, 2013, p. 259). Indigenous leadership should be an important aspect of evaluating sustainable development (Wehipeihana, 2019). Blue marble evaluation is a principles-based global initiative that brings together many of the above notions, incorporating environmental sustainability as central (Patton, 2020). Brousselle and McDavid (2020) remind us that social betterment is a goal for all evaluators, but we have to rethink what it means as we have entered Anthropocene. Evaluators can no longer ignore human-induced environmental degradation, which poses a direct threat to our health and wellbeing.

Taking a comprehensive view to evaluating complex issues, such as adaptation to climate change, is increasingly important. While immediate challenges such as protection against sea-level rise and coastal storms or coping with climate variability must receive urgent priority, it is also necessary to go beyond them and address the root causes of vulnerability, which are most often structural, often related to power, inequality, and historical factors (see example in Box 1). 
Box 1. Illegal wildlife trade

The GEF has for some time funded work related to illegal wildlife trade, a topic of significance to biodiversity conservation. Much biodiversity loss is caused by poaching, which is primarily driven by demand for wildlife products in a market outside of the source areas. For example, rhino horn has a market in East Asia, notably in China, where it is used in traditional Chinese medicine. There is evidence that funding for large-scale poaching in Africa originates outside of the continent. Places like Hong Kong and Bangkok serve as major trading centres for products like rhino horn and ivory. There are other important aspects of illegal wildlife trade, like those pertaining to exotic birds and reptiles from South America that have large markets in North America and Europe. Illegal wildlife trade has suddenly been brought to the limelight by the COVID-19 pandemic due to its zoonotic roots. China's wildlife trade has been investigated by the World Health Organization (WHO) for its role in the current pandemic (Mallapaty, 2020).

The Independent Evaluation Office conducted a formative evaluation of the GEF programme on illegal wildlife trade. While this was conducted prior to the current pandemic, it was later deemed that the programme and others like it are instrumental in controlling and preventing the spread of zoonotic infectious diseases that result in epidemics and pandemics (GEF IEO, 2020b). A fundamental conclusion was that it is essential to look beyond the immediate areas where a problem manifests itself and identify the drivers. Addressing livelihood issues in source countries is important to reduce the need of local communities to engage in poaching in the first place, but the evaluation highlights the importance of taking a more holistic approach to solving problems, such as a globally co-ordinated approach that places a focus on the countries and markets that fuel demand. It is also essential to address a continuum of factors from 
political will and corruption at the source, to the transit and destination countries.

Rowe (2012) has reminded us that interests and goals of resource users in the same geographical space may differ significantly. Therefore, a climate-adaptation project that focuses just on drought-resistant agriculture in an area affected by climate change may succeed in most of its internal goals (for example, increasing crop yields and reducing productivity losses). But it may have unintended long-term consequences if it does not account for the needs of different groups and focus on sustainability and local values. For instance, small and marginal farmers may not have the land or adequate finances to purchase the inputs for producing certain crops. Further, the land may not be suited for the utilisation of certain types of crops and technologies. The project may thus end up further increasing the gap between the rich and the poor (including female farmers). And it may drive the poor farmers out of an area where they have farmed for generations, causing migration away from traditional homelands towards urbanisation and less self-sufficiency.

Evaluations must therefore look beyond what the project intended to achieve and also focus on the unintended consequences, and the broader factors contributing to them. Many of these are likely to be outside of the scope of the original project and may pertain to things such as land tenure, vested interests, perverse subsidies, and skewed markets. There are also complex factors and dynamics related to the natural environment that have a bearing on the intervention. Although they are beyond its control, they are all determinants of its success. If they are not addressed adequately, it implies the project was not appropriately designed and could not achieve success. Evaluators must be able to point this out. For evaluation to be able to address these issues will require multidisciplinary and interdisciplinary 
approaches that cross dimensions, such as social, political, economic, and environmental, and may use other knowledges (including those vested in indigenous peoples and other minorities) next to science. This is particularly important because the issues pertaining to ecosystem health, climate change, adaptation, natural-resources management, and biodiversity conservation are increasingly complex, and straddle interconnected human and natural systems (CHANS). These typically take place at the nexus of environment and development. Mixed methods, both quantitative and qualitative-or what Patton (2020, p. 102) has called bricolage methods_-will become the norm.

Accountability for achieving results is more important than ever, but there are other mechanisms for measuring and enhancing project-level accountability for resource use, including performance audit and monitoring. Evaluation provides accountability where we can learn from the past (reflection) to ensure that we do the right things for the future. It is therefore important to focus on accountability from different perspectives and not assume that all stakeholders share the same objectives. Instead of only focusing on downward accountability from the perspective of the donors or funders, the focus must primarily be on upward accountability from the intended beneficiaries. Social justice and inclusion are prerequisites for sustainable development and therefore must also be underlying principles for evaluators.

\section{Conclusion}

The year 2020 (and the year after that) will go down to history as an annus horribilis, marked by a deadly pandemic, devastating wildfires, cyclones, and melting ice sheets, as well as societal and racial tensions and threats to freedom and democracy around the world. It has demonstrated in no uncertain terms that even advanced societies 
cannot control nature. We must move towards transformational change and the 2020s will be the decade to act. It may well be our last chance before climate change permanently renders large swathes of the globe hostile to habitation thus causing widespread conflict, migrations, and food insecurity.

With the learnings from the current pandemic, we must build back better and greener. We must have a vision for the kind of future we want, a future hopefully more socially, economically, and environmentally sustainable, with a focus on equity and social justice. We must learn to respect the natural environment and one another, and understand the importance of natural capital on which all our wellbeing depends. This will require us to think about the shape and size of our cities, our landscapes, transportation systems, food systems, fisheries, forest management, energy, and all the other essential dimensions of the human endeavour. Whatever we do now, and however fast we do it, it is already too late to stop the effects of climate change. Adaptation is necessary and will require significant transformations in the way we live and organise society.

Evaluation can make an important contribution-with knowledge, lessons, analysis of past experiences - in each and all of the areas discussed above. As I have argued in this article, it is essential to use a systems approach that incorporates across the perspectives of social and natural sciences, paying attention to cultural diversity. Evaluation must focus on learning, from previous interventions and evaluations, and to build upon existing knowledge from science. It also must learn from indigenous knowledge around the world and to assume a holistic perspective to ecosystem and human health, where the rights of nonhumans are respected and where humans are not seen as separate from the rest of the planetary web of life. 


\section{Acknowledgements}

I would like to acknowledge my colleagues who led the GEF IEO evaluations referred to in this article: Geeta Batra, Anupam Anand, Carlo Carugi, Jeneen Garcia, Kseniya Temnenko, and Anna Viggh. I would also like to thank Fiona Cram, Andy Rowe, and three anonymous reviewers for their constructive comments on the draft versions of the article.

\section{References}

Aguirre, J. C. (2020). Toward the desert: In Central America climate change is driving people north. Sierra, 105(5), 28-35.

Aluli-Meyer, M. (2013). The context within: My journey into research. In D. M. Mertens, F. Cram, \& B. Chilisa (Eds.), Indigenous pathways into social research: Voices of a new generation (pp. 249-260). Left Coast Press.

Asokan, G. V., \& Asokan, V. (2016). Bradford Hill's criteria, emerging zoonoses, and One Health. Journal of Epidemiology and Global Health, 6(3), 125-129. https://doi.org/10.1016/j.jegh.2015.10.002

Baer, H. A., \& Singer, M. (2018). The anthropology of climate change: An integrated critical perspective. Routledge. https://doi. org/10.4324/9781351273121

Bickman, L., \& Reich, S. M. (2009). Randomized controlled trials: A gold standard with feet of clay? In S. I. Donaldson, C. Christie, \& M. M. Mark (Eds.), What counts as credible evidence in applied research and evaluation practice? (pp. 51-77). Sage. https://doi.org/10.4135/9781412995634.d10

Birnbaum, M., \& Micwitz, P. (Eds.). (2009). Environmental program and policy evaluation: Addressing methodological challenges. New Directions for Evaluation, 122. Jossey-Bass and the American Evaluation Association.

Brack, D., Glover, A., \& Wellesley, L. (2016). Agricultural commodity supply chains: Trade, consumption and deforestation. Research paper. Chatham House. 
Brousselle, A., \& McDavid, J. (2020). Evaluators in the Anthropocene. Evaluation, 26(2), 190-204. https://doi.org/10.1177/1356389020911060 Burke, M., Hsiang, S. M., \& Miguel, E. (2015). Global non-linear effect of temperature on economic production. Nature, 527, 235-239. https://doi. org/10.1038/nature15725

CPI (Naran, P., Fernandes, P., Padmanabhi, R., Rosane, P., Solomon, M., Stout, S., Strinati, C., Tolentino, R., Wakaba, G., Zhu, Y., \& Buchner, B.). (2021). Global landscape of climate finance 2021. Climate Policy Initiative. https://www.climatepolicyinitiative.org/publication/ global-landscape-of-climate-finance-2021/

Ford, J. D., King, N., Galappaththi, E. K., Pearce, T., McDowell, G., \& Harper, S. L. (2020). The resilience of indigenous peoples to environmental change. One Earth, 2, 532-543. https://doi.org/10.1038/ nature15725

Fuchs, R., Conran, M., \& Louis, E. (2011). Climate change and Asia's coastal urban cities: Can they meet the challenge? Environment and Urbanization Asia, 2(1), 13-28. https://doi.org/10.1177/097542531000200103

Fukuyama, F. (2006). The end of history and the last man. Free Press.

Fukuyama, F. (2020). The pandemic and political order: It takes a state. Foreign Affairs, 99(4), 26-32.

GCA. (2019). Adapt now. A global call for leadership in climate resilience. Global Commission on Adaptation and World Resources Institute. https:// cdn.gca.org/assets/2019-09/GlobalCommission_Report_FINAL.pdf

GEF. (2018). Guidance to advance gender equality in GEF projects and programs. Author. http://www.thegef.org/publications/ gef-guidance-gender-equality

GEF IEO. (2017). Evaluation of multiple benefits of GEF's multifocal area (MFA) portfolio. Author. https://www.gefieo.org/evaluations/evaluationmultiple-benefits-gef-support-through-its-multifocal-area-portfoliomap-2016

GEF IEO. (2018a). Value for money analysis for GEF land 
degradation projects. Author. https://www.gefieo.org/evaluations/ value-money-analysis-land-degradation-projects-gef-2016

GEF IEO. (2018b). Impact of GEF support on national environmental laws and policies. Author. http://www.gefieo.org/evaluations/impact-gef-supportnational-environmental-laws-and-policies-selected-countries-2017

GEF IEO. (2018c). Evaluation of GEF support for transformational change. Author. http://www.gefieo.org/evaluations/ evaluation-gef-support-transformational-change-2017

GEF IEO. (2018d). Evaluation of gender mainstreaming in the GEF. Author. https://www.gefieo.org/evaluations/ evaluation-gender-mainstreaming-gef-2017

GEF IEO. (2020a). Strategic country cluster evaluation: Sahel and SudanGuinea savanna biomes. Author. https://www.gefieo.org/evaluations/ african-biomes-strategic-country-cluster-evaluation-scce

GEF IEO. (2020b). The GEF response to crisis: What can we learn from evaluation? Author. https://www.gefieo.org/documents/ report-gef-response-crisis-what-can-we-learn-evaluation-report

Han, A., \& Freymann, E. (2021, 11 March). China's new five-year plan is a disappointment. Foreign Policy. https://www.sixthtone.com/news/1007199/ gep $\% 2 \mathrm{C}$-a-green-alternative-to-gdp $\% 2 \mathrm{C}$-gaining-ground-in-china

Mallapaty, S. (2020). Scientists call for pandemic investigations to focus on wildlife trade. Nature, 583, 344. https:/doi.org/10.1038/ d41586-020-02052-7

McGill, E., Er, V., Penney, T., Egan, M., White, M., Meier, P., Whitehead, M., Lock, K., Anderson de Cuevas, R., Smith, R., Savona, N., Rutter, H., Marks, D., de Vocht, F., Cummins, S., Popay, J., \& Petticrew, M. (2021). Evaluation of public health interventions from a complex systems perspective: A research methods review. Social Science \& Medicine, 272, 113697. https://doi.org/10.1016/j.socscimed.2021.113697

McMichael, C., Dasgupta, S., Ayeb-Karlsson, S., \& Kelman, I. (2020). A review of estimating population exposure to sea-level rise and the 
relevance for migration. Environmental Research Letters. https://doi. org/10.1088/1748-9326/abb398

Mertens, D.M. (2008). Transformative research and evaluation. Guilford Press.

Moran, G. (2020, 22 September). NOAA is changing the way it talks about hurricanes. Popular Science. https://www.popsci.com/story/environment/ hurricane-risk-communication/

Parry, I., Black, S., \& Vernon, N. (2021). Still not getting energy prices right: A global and country update on fossil fuel subsidies. IMF Working Paper 2021/236. https://www.imf.org/en/Publications/WP/Issues/2021/09/23/ Still-Not-Getting-Energy-Prices-Right-A-Global-and-Country-Update-ofFossil-Fuel-Subsidies-466004

Patton, M. Q. (2020). Blue marble evaluation: Premises and principles. Guilford Press. https://doi.org/10.31244/zfe.2020.02.09

Picciotto, R. (2020). Towards a complexity framework for transformative evaluation. Journal of MultiDisciplinary Evaluation, 16(35), 54-75. https:// journals.sfu.ca/jmde/index.php/jmde_1/article/view/643/533

Rodriguez Mega, E. (2020). 'Apocalyptic' fires are ravaging the world's largest wetland. Nature. https://doi.org/10.1038/d41586-020-02716-4

Rowe, A. (2012). Evaluation of natural resource interventions. American Journal of Evaluation, 33(3), 384-394. https:/doi. org/10.1177/1098214012440026

Staal, A., Fetzer, I., Wang-Erlandsson, L., Bosmans, J. H. C., Dekker, S. C., van Nes, E. H., Rockström, J., \& Tuinenburg, O. A. (2020). Hysteresis of tropical forests in the 21st century. Nature Communications, 11, 4978. https://doi.org/10.1038/s41467-020-18728-7

Stame, N. (2004). Theory-based evaluation and types of complexity. Evaluation, 10(1), 58-76. https://doi.org/10.1177/1356389004043135

Surjan, A., Kudo, S., \& Uitto, J. I. (2016). Risk and vulnerability. In J. I. Uitto \& R. Shaw (Eds.), Sustainable development and disaster risk reduction (pp. 37-55). Springer. https://doi.org/10.1007/978-4-431-55078-5_3 
Tollefson, J. (2020). Why deforestation and extinctions make pandemics more likely. Nature, 584, 175-176. https://doi.org/10.1038/ d41586-020-02341-1

Tucker, C. (2019). A planet of 3 billion. Atlas Observatory Press.

UN. (2015). Small island developing states in numbers: Climate change edition 2015. United Nations Office of the High Representative for the Least Developed Countries, Landlocked Developing Countries and Small Island Developing States (UN-OHRLLS). https://sustainabledevelopment. un.org/content/documents/2189SIDS-IN-NUMBERS-CLIMATECHANGE-EDITION_2015.pdf

UN. (2019). World population prospects 2019: Highlights. United Nations Department of Economic and Social Affairs (UNDESA). https:// population.un.org/wpp/Publications/Files/WPP2019_Highlights.pdf

UNDP. (2020). Human development report 2020: The next frontierHuman development and the Anthropocene. Author. http://hdr.undp.org/ en/2020-report

Wehipeihana, N. (2019). Increasing cultural competence in support of indigenous-led evaluation: A necessary step toward indigenous-led evaluation. Canadian Journal of Program Evaluation, 34(2), 368-384. https://doi.org/10.3138/cjpe.68444

Weiss, C. H. (1997). Theory-based evaluation: Past, present and future. New Directions for Evaluation, 76, 41-55. Jossey-Bass and the American Evaluation Association. https://doi.org/10.1002/ev.1086

Williams, B. (2015). Prosaic or profound? The adoption of systems ideas by impact evaluation. IDS Bulletin, 46(1), 7-16. https://doi. org/10.1111/1759-5436.12117

Worster, D. (2016). Shrinking the earth: The rise and decline of American abundance. Oxford University Press.

Ye, Y. (2021). GEP, a green alternative to GDP, gaining ground in China. Sixth Tone. https://www.sixthtone.com/news/1007199/ gep $\% 2 \mathrm{C}$-a-green-alternative-to-gdp $\% 2 \mathrm{C}$-gaining-ground-in-china 


\section{The author}

Juha I. Uitto is Director of the Global Environment Facility (GEF) Independent Evaluation Office. He has worked for over two decades as an evaluator in international organizations focusing on the nexus of environment and development.

Email: juitto@thegef.org 